\title{
A seven-year retrospective review of colonoscopy records from a single centre in Zambia
}

\author{
Violet Kayamba ${ }^{1}$, Kate Nicholls ${ }^{2}$, Catrin Morgan ${ }^{2}$, Paul Kelly ${ }^{1,2}$ \\ 1. Tropical Gastroenterology \& Nutrition group, University of Zambia School of Medicine, Nationalist Road, \\ Lusaka, Zambia. \\ 2. Blizard Institute, Barts \& The London School of Medicine and Dentistry, Queen Mary University of London, \\ 4 Newark Street, London E1 2AT, United Kingdom.
}

*Corresponding author: Violet Kayamba; viojole@yahoo.com

Date Received: 18 February 2016

Revision Received: 28 February 2017

Date Accepted: 01 March 2017

Correspondence:

Dr. Adetunji Obadeji

(doctunjioba@yahoo.com)

\section{Introduction}

https://dx.doi.org/10.4314/mmj.v30i1.4

Colorectal disease is common throughout the world, but the spectrum of diagnoses across Africa remains largely unexplored. There is anecdotal evidence of changing colorectal disease but this has not been systematically investigated. The aim of this study was to enhance our insight into the spectrum of colonoscopic diagnoses in Zambia.

Methods

We retrieved written colonoscopy reports from January 2008 to December 2015. Collected data were coded by experienced endoscopists and analysed by age, sex, referral source, indication and diagnosis.

Results

Included in this analysis were 573 colonoscopy reports. The most common diagnosis was haemorrhoids ( $\mathrm{n}=151,26 \%)$, followed by tumours $(\mathrm{n}=96,17 \%)$. Over this time period, the proportion of normal colonoscopies decreased by $32 \%$ (P<0.001), presumably due to introduction of screening of all requests, while the rate of polyp detection increased from $5 \%$ to $10 \%(\mathrm{P}=0.006)$. The detection of polyps was highest in patients less than 16 years (OR 8.4; 95\% CI 2.4-26.2, P<0.001). Of those with colorectal tumours, 33/96 (35\%) were less than 45 years although the occurrence was higher with advancing age $(\mathrm{P}=0.02)$. Diverticular disease was more common in older age groups (median (IQR) age 70 (60-75) years, versus 47 (34-62) years for those without the disease; $\mathrm{P}=0.0001$ ).

Conclusion

This audit has shown that more than a third of colorectal tumours seen during colonoscopy are in patients below the age of 45 years, with the occurrence of polyps being highest in those below 16 years. Diverticular disease is most common in older age groups.

\section{Introduction}

Colonoscopy services are now available in many parts of Africa, with varying disease spectra being reported. These services however remain fragmented and at best serve urban communities. The understanding of colonic pathology in many African communities remains unclear due to under reporting and poor detection methods. Even in areas in which the services are available, waiting time can be as long as eight weeks ${ }^{1}$.

Common colonoscopic diagnoses include cancer, diverticular disease, inflammatory diseases, polyps and haemorrhoids. Globally, colorectal cancer is the third most common cancer in men and the second in women, and has much higher incidence in developed countries ${ }^{2}$. Colorectal cancer was previously thought to be rare in Africa but there are now reports of increasing prevalence in some African communities $^{3}$. Nevertheless, it remains unclear if this is a real increase or just a reflection of improved diagnostic and reporting capabilities. Similar to colorectal cancer, diverticular disease was thought to be rare in Africa, but evidence is emerging in support of a higher prevalence of the disease than previously believed ${ }^{4,5}$. However, the exact burden of diverticular disease in sub-Saharan Africa is not clear but it has been reported to be significantly higher among whites than blacks ${ }^{6}$. It is known that only $10-20 \%$ of individuals with diverticular disease present with symptoms making it difficult to ascertain prevalence in countries that do not offer screening colonoscopies ${ }^{7}$. In developed countries such as $\mathrm{UK}$, diverticular disease is increasing ${ }^{8,9}$ while in USA, it is the sixth most common gastrointestinal diagnosis ${ }^{10}$. The most common colonoscopic diagnosis in many African centers is haemorrhoids, ${ }^{11,12,13}$ and figures are not far off the high prevalent numbers found in developed nations ${ }^{14}$.

The endoscopy unit at the University Teaching Hospital (UTH) in Lusaka, Zambia started offering upper gastrointestinal endoscopic services in 1977'15. However, it was not until 2008 that the unit started offering regular colonoscopy services. The spectrum of colonic diagnoses in Zambia remains unreported and therefore changes in disease profiles are unknown. In this study, we reviewed all the available colonoscopy records analyzing diagnostic time trends and common conditions detected.

\section{Methods}

All available colonoscopy records since the inception of the services at the University Teaching Hospital (UTH) in 2008 were retrieved. The UTH is a national referral hospital attending to patients from all the ten provinces of Zambia (Unpublished records show that more than a third of these patients are from outside Lusaka). From 2008, reports were hand-written and carbon copies were kept. A computerbased recording system was implemented during this time but written reports were still used as back ups. The use of computerized records made it possible to adopt more standardized terminology for ease of comparison. When entering the data, no patients' names were used. Information obtained from these records included sex, age, year of procedure, indication, diagnosis and referral source. For the last three years (2013-2015), the endoscopists were also recorded. KN and CM entered free text into a spreadsheet as documented by the endoscopies and the information 
was coded by VK. The University of Zambia Biomedical Research Ethics Committee granted exemption from ethics review for this retrospective analysis on 22nd January 2015.

\section{Coding of indications and diagnoses}

Free text entries were coded as follows:

1. Indication: these were summarized as either, "diarrhoea", "per rectal bleeding or blood in stools", "recurrent constipation", "abnormal imaging", "rectal mass or rectal lesion", "surveillance", "screening" or "follow-up", "abdominal pain", "anemia", "melaena", "abdominal mass", and "mucoid discharge".

2. Diagnosis: "Normal", "diverticula", "colitis", "proctitis", "haemorrhoids", "poor bowel preparation", "anal fissure", "telangiectasia", "polyp, non-specific", "erythematous mucosa", "fissure", "tumour", "non-specific ulceration", "fistula", "blue-rubber-bleb", "distended bowel", "stricture", "radiation damage", "megacolon", "venous malformation".

\section{Data analysis}

Data were analysed using STATA 13 (Stata Corp, College Station TX). Age was summarized using medians with interquartile ranges. Diagnostic categories were dichotomized and analysed by frequency; and two-way analyses were carried out using Fisher's exact to look for various associations. Trend tests were also used to assess the odds ratios in various categories. Odds ratios with 95\% confidence intervals were derived and $\mathrm{P}$ values less than 0.05 were considered statistically significant.

\section{Results}

A single endoscopist, PK, performed $77 \%$ of all colonoscopies done between 2013 and 2015. Of the 687 reports retrieved, $483(70 \%)$ were reports of full colonoscopies and 204 $(30 \%)$ were either flexible sigmoidoscopies or incomplete colonoscopies. From these reports, $79(12 \%)$ had no definitive diagnosis due to poor bowel preparation and 35 $(5 \%)$ had either illegible or unclear diagnosis leaving 573 reports with complete and clear diagnoses. Therefore in the final analysis, 573 reports were included of which 127 $(22 \%)$ were flexible sigmoidoscopies. This analysis showed that $211(37 \%)$ were female, $315(55 \%)$ were males and sex was not specified in $47(8 \%)$. There was no significant age difference between the two sexes (Table 1). Reports with the referral source indicated showed that 345/428 (80\%) were from within the UTH. The most common diagnosis during this time period was haemorrhoids in 151/573 (26\%) followed by tumours in 96/573 (17\%), (Figure 1).

Table 1: Colonoscopic diagnoses in females and males

\begin{tabular}{|l|c|c|c|}
\hline & Females, $\mathrm{n}=211(\%)$ & Males, $\mathrm{n}=315(\%)$ & $P$ \\
\hline Age, median (IQR) & $49(37-61)$ & $45(34-62)$ & 0.35 \\
\hline Haemorrhoids & $46(22)$ & $93(30)$ & 0.06 \\
\hline Diverticula & $4(2)$ & $10(3)$ & 0.42 \\
\hline Tumour & $38(18)$ & $50(16)$ & 0.55 \\
\hline Polyps & $16(8)$ & $24(8)$ & 1.00 \\
\hline Colitis & $15(7)$ & $12(4)$ & 0.11 \\
\hline
\end{tabular}

*Interquartile range (IQR)
Table 2: Table showing the odds of diagnosing normal colonoscopy and finding poorly prepared bowels by year.

\begin{tabular}{|c|c|c|c|c|}
\hline Year & $\begin{array}{c}\text { Normal } \\
\text { colonoscopies } \\
\text { n (\%) }\end{array}$ & Odds; $95 \%$ CI & $\begin{array}{c}\text { Poor bowel } \\
\text { preparation, } \\
\text { n (\%) }\end{array}$ & Odds; $95 \%$ CI \\
\hline 2009 & $15(48)$ & $0.9 ; 0.4-1.9$ & $5(14)$ & $0.2 ; 0.1-0.4$ \\
\hline 2010 & $28(41)$ & $0.7 ; 0.4-1.1$ & $16(19)$ & $0.2 ; 0.1-0.4$ \\
\hline 2011 & $27(34)$ & $0.5 ; 0.3-0.8$ & $21(21)$ & $0.3 ; 0.2-0.4$ \\
\hline 2012 & $29(41)$ & $0.7 ; 0.4-1.1$ & $12(15)$ & $0.2 ; 0.1-0.3$ \\
\hline 2013 & $35(33)$ & $0.5 ; 0.3-0.7$ & $4(4)$ & $0.03 ; 0.01-0.1$ \\
\hline 2014 & $15(16)$ & $0.2 ; 0.1-0.3$ & $5(5)$ & $0.05 ; 0.02-0.1$ \\
\hline 2015 & $20(16)$ & $0.2 ; 0.1-0.3$ & $15(11)$ & $0.1 ; 0.07-0.2$ \\
\hline $\begin{array}{l}{ }^{*} \text { Trend } \\
\text { of odds } \\
P=0.0001 \\
P=0.001\end{array}$ & & & & \\
\hline
\end{tabular}

*Using the score test for trend of odds, the reduction in odds was statistically significant in both cases, $P=0.0001$ and $P=0.001$ respectively.

Table 3: Detection of tumours during colonoscopy in relation to indication

\begin{tabular}{|c|c|c|c|c|}
\hline Indication & $\begin{array}{l}\text { Tumour seen } \\
\mathrm{n}=96(\%)\end{array}$ & $\begin{array}{l}\text { No tumour } \\
\text { seen } \\
n=477(\%)\end{array}$ & OR; $95 \%$ CI & $P$ \\
\hline Rectal lesion & $11(12)$ & $15(3)$ & $4.0(1.6-9.7)$ & 0.001 \\
\hline Melaena & $0(0)$ & $6(1)$ & - & 0.596 \\
\hline Aneamia & $6(6)$ & $33(7)$ & $0.9(0.3-2.2)$ & 1.000 \\
\hline $\begin{array}{l}\text { Positive fecal } \\
\text { occult blood }\end{array}$ & $0(0)$ & $5(1)$ & - & 0.596 \\
\hline Rectal bleeding & $45(47)$ & $255(54)$ & $0.8(0.5-1.2)$ & 0.263 \\
\hline Diarrhoea & $4(4)$ & $32(7)$ & $0.6(0.2-1.8)$ & 0.489 \\
\hline Constipation & $3(3)$ & $12(3)$ & $1.3(0.2-4.8)$ & 0.725 \\
\hline Abdominal mass & $7(8)$ & $4(1)$ & $9.4(2.3-44.2)$ & $<0.001$ \\
\hline Abdominal pain & $2(2)$ & $24(5)$ & $0.4(0.04-1.7)$ & 0.285 \\
\hline
\end{tabular}

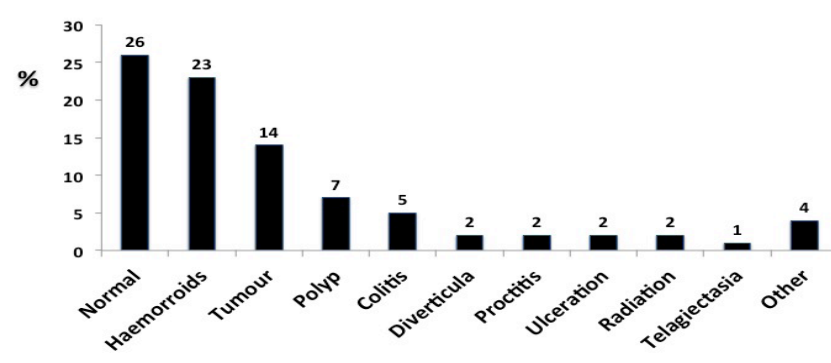

Figure 1: Frequencies of various colonoscopic diagnoses. Included in other diagnoses are anal fissures, fistula, non-specific erythematous mucosa, megacolon, stricture, blue-rubber-bleb and venous malformation 


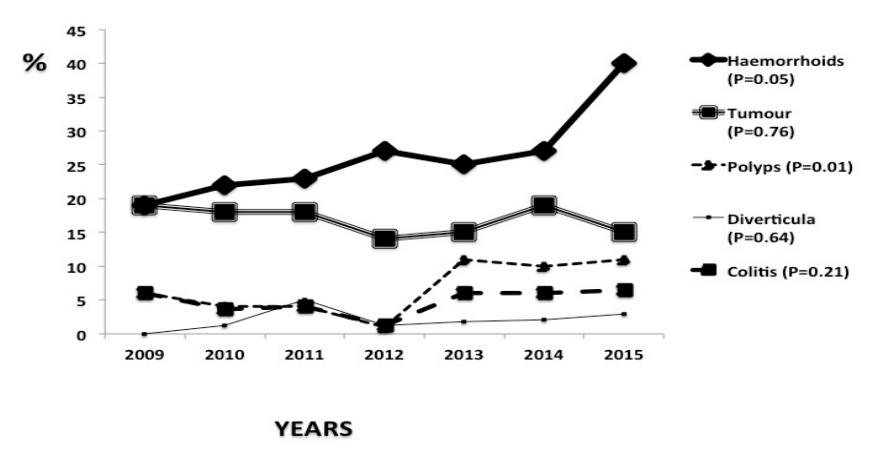

Figure 2: Diagnostic trends for the five most common conditions $254 \times 190 \mathrm{~mm}(72 \times 72 \mathrm{DPI})$

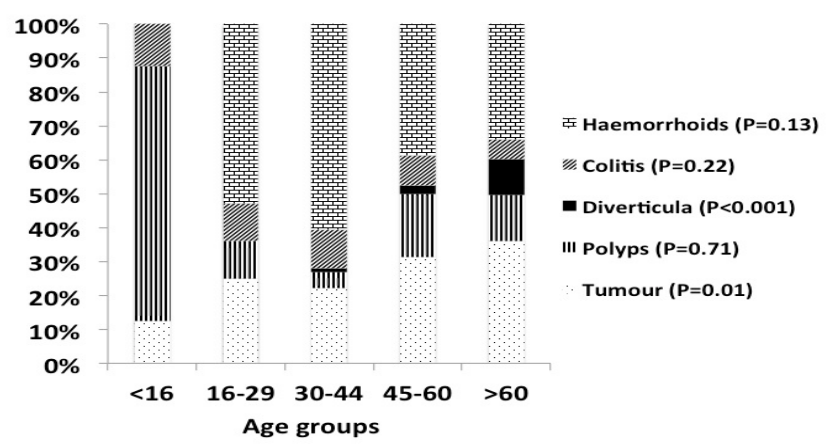

Figure 3: Using nptrend test for trend to analyse common colonoscopic findings by age group $254 \times 190 \mathrm{~mm}$ (72 x 72 DPI)

\section{Time trends in colonoscopic diagnoses}

Overall, the proportion of normal colonoscopies decreased from $48 \%$ in 2009 to $16 \%$ in 2015 . In addition, analyses using the score test of odds showed a statistically significant decreasing trend in reporting normal colonoscopies, $(\mathrm{P}=0.0001)$. The diagnosis of polyps increased significantly from $5 \%$ in 2009 to over $10 \%$ in 2015, (Figure 2). The diagnosis of colonic tumours remained consistent throughout this period $(p=0.76)$ (Figure 2). The least common diagnoses were not included in the analysis of time trends.

\section{Inadequate bowel preparation}

The odds of incomplete procedures due to poor bowel preparation reduced during the seven years, $\mathrm{P}=0.001$. Of note were the years 2013 and 2014 when the proportions were particularly low, $4 \%$ and $5 \%$ respectively. Poor bowel preparation was not associated with age, $\mathrm{P}=0.8$.

\section{Colonictumours (withouthistologicalconfirmation)}

The endoscopists saw a total of 96 colonic tumours during this time period, with no significant difference between males and females (Table 1). 33/96 (35\%) of those with colonic tumours were below the age of 45 years and among these, five were aged below 20 years, the youngest being 15 years. Using Cuzick's non-parametric test for trend, colonic tumours significantly increased with advancing age, $\mathrm{P}=0.02$, (Figure 3). Tumour diagnosis was associated with clinically detected rectal lesions or abdominal masses but not melaena or positive fecal occult blood testing.

\section{Polyps}

Polyps were detected in 44/573 (8\%) of the patients. Two of these patients were from Peutz-Jeghers families and one from a family with Familial Adenomatous Polyposis. The detection of polyps was significantly higher among patients less than 16 years old compared to adults, OR 8.4; 95\% CI 2.4-26.2, $\mathrm{P}<0.001$. However, there was no overall trend across the age groups noted, $\mathrm{P}=0.6$, (Figure 3 ). There was no significant difference in polyp detection by endoscopist, although the numbers of procedures done by some was too few to enable meaningful comparisons, $\mathrm{P}=0.53$.

\section{Diverticular disease}

Overall, 14/573 (2\%) of the patients had diverticular disease and of these, $11(79 \%)$ presented with rectal bleeding. The youngest patient with diverticular disease was 42 years old and the diagnosis increased significantly with advancing age. The median (IQR) for those with diverticular disease was 70(60-75) versus 47(34-62) in those without the disease $\mathrm{P}=0.0001$; Figure 3 .

\section{Haemorrhoids}

Haemorrhoids were more common among patients below the age of 45 years (OR 1.7; 95\% CI 1.1-2.5, $\mathrm{P}=0.007$ ) but did not differ significantly by sex (Table 1). The presence of haemorrhoids was associated with rectal bleeding and this was statistically significantly, OR 3.9; 95\% CI 2.5-6.0, $\mathrm{P}<0.001$.

\section{Discussion}

In this small seven-year colonoscopy audit, we report the profile of diagnoses made. Overall, haemorrhoids were the most common findings closely followed by tumours. We found that the detection of polyps increased over this time period and was very common in patients less than 16 years. More than a third of patients with tumours diagnosed during colonoscopy were below the age of 45 years but, in contrast, diverticular disease was only present in older patients.

Bowel preparation for colonoscopy in this unit was inconsistent during this time period. The proportion of incomplete procedures due to poor bowel preparation was lowest during the years a commercially obtained osmotic laxative was available in this unit (i.e. 2013 - 2014). For most years, patients had to either buy the bowel preparation using out of pocket funds or rely on left over samples from research studies. Due to economic hardships in Zambia, many patients are unable to afford the prescribed bowel preparation. Over the seven years, $12 \%$ of the procedures could not be completed due to poor bowel preparation. Our findings are similar to a study carried out in Tunisia, in which they reported $18 \%$ of colonoscopies not completed due to inadequate colonic preparation ${ }^{16}$. In contrast, statistics from the UK show a proportion less than $2 \%{ }^{17}$ a figure not very different from those for the two years when bowel preparation medications were readily available in our unit. It is generally thought that older age is associated with less satisfactory bowel preparation ${ }^{18}$. Our data however showed no influence of age on the occurrence of poor bowel preparation.

This audit showed a decrease of normal colonoscopies over the course of seven years. When the unit first opened, almost $50 \%$ of the procedures showed normal findings, but by 2015 the proportion had reduced to $16 \%$. One factor influencing this reduction could have been the introduction of a new policy requiring all request forms to be reviewed by a gastroenterologist. This strategy was put in place in order 
to assess the appropriateness of all referrals. An audit done in Zimbabwe found that $52 \%$ of the colonoscopies were normal, while in Nigeria it was $29 \% 0^{6,11}$.

The incidence of colorectal cancer in Zambia remains uncertain. There is evidence of racial disparities in the occurrence of colorectal cancer, even within the same geographical location. Graham et al reported that colorectal cancer was more common among whites and least among blacks in sub-Saharan Africa ${ }^{19}$. Similarly, in Zimbabwe, colorectal cancer was more common in Caucasians than other racial groups.6 In contrast, colorectal cancer in the United States is most common among black men ${ }^{20}$. This could be an actual racial and regional difference but it could also mean that colorectal cancer in black Africans is being underreported. Furthermore, Katsidzira et al found that black colorectal cancer patients in Zimbabwe were significantly younger than their Caucasian counterparts. These finding are similar to those of a study in Nigeria which found that the mean age of colorectal cancer patients was lower than that of Western countries; 3 suggesting that the findings reported in this study are part of a more general phenomenon. In Egypt it was reported that $22 \%$ of colorectal cancer patients were below the age of 40 years $^{21}$. In the USA, only $5.7 \%$ of colorectal cancer patients were below the age of 45 years with a median age at diagnosis of 68 years $^{22}$. We do not believe that these age discrepancies are merely due to the young population structures in Africa. If that were the case, all disease conditions would be equally affected. In this audit, for example, we found that over the seven years there was no patient below the age of 40 years with the diagnosis of diverticular disease, a profile similar to statistics from western countries such as the $\mathrm{UK}^{8}$. Unexplored in this population is the genetic predisposition to colorectal cancer, but in this study we know of only three patients who had a clear-cut genetic syndrome. This highlights a potential area where further research is warranted to obtain a more definitive conclusion.

There is paucity of information on colonic polyps in Zambia. The occurrence of colonic polyps is generally thought to be lower among Africans, and in this series the largest proportion of polyps were in younger patients. We found a prevalence of $8 \%$ in this audit, a figure similar to Zimbabwe in which they found that $5 \%$ of black patients had colonic polyps. 6 Similarly, the figures for Nigeria and Kenya were $10.3 \%$ and $6.5 \%$ respectively ${ }^{11,23}$. A meta-analysis from the United States reported the overall prevalence of adenomatous polyps to be $30 \%{ }^{24}$.

Diverticular disease was once thought to be rare in Africans. Alatise et al identified 40 patients over a five-year period and Segal et al detected 42 cases in 3 years among black South Africans ${ }^{4,25}$. However these figures are still much lower than in developed countries. Questions have been raised as to whether urbanization of rural parts of Africa and the introduction of a western diet with lower fibre content has been a cause of the increase in diverticular disease $e^{26,27}$. However, this link has been questioned in a cross-sectional study and during clinical observation in Thailand where diet was not associated with the prevalence of diverticular disease $^{28,29}$. In our study, the majority of diverticular disease was right-sided, in contrast to the European or North American distribution.

The exact incidence of haemorrhoids is difficult to ascertain, as many patients with minor lesions do not seek medical advice. In this audit, haemorrhoids were the most common diagnosis with a prevalence of $26 \%$ similar to Nigeria where they reported a proportion of $21 \%{ }^{11}$. Interestingly, another study from Nigeria reported the prevalence as high as $43 \%{ }^{12}$. The same pattern of disease diagnosis is seen in the developed world. Riss et al from Austria noted that 39\% of their study participants suffered from haemorrhoids ${ }^{30}$. Rectal bleeding is a common presentation in patients with haemorrhoids. Nigeria reports an older population of patients acquiring haemorrhoids, the highest frequency being in the 61-70 age group; which correlates with Austria's mean age of haemorrhoid diagnosis of 61.68 years $^{11,30}$. Korea reports a slightly lower age group, 40-59 years ${ }^{31}$.

In this study, the mean age was 43 years. High body mass index (BMI) has been linked to the development of haemorrhoids ${ }^{30,32}$, but we did not have data on BMI in this audit. This was the first colonoscopy audit done in a Zambian population but had the limitation of incomplete entries. This reduced the number of reports included in the final analysis.

The lack of histological confirmation of the tumours seen during endoscopy is another limitation of this retrospective audit.

In conclusion, the profile of disease detected during colonoscopy in Zambia is similar to other centers in Africa, with a much younger population of individuals with colorectal tumours.

\section{Acknowledgements}

We would like to acknowledge the endoscopy nurse-incharge, Themba Banda, for availing us the colonoscopy records and Richard Miti for collecting some data for this audit.

\section{Funding}

This work was not funded

\section{Disclosure statement}

No conflicts of interest for declaration by any of the authors

\section{Author contributions}

PK initiated the idea for the audit. VK, KN and CM collected the data. VK and PK did data analysis. All authors contributed to the intellectual content of the manuscript.

\section{References}

1. Watermeyer G, Van Wyk ME, Goldberg PA. Audit of provincial gastroenterology services in the Western Cape. S Afr J Surg. 2008 Aug; 46(3): 68-72.

2. Ferlay J, Soerjomataram I, Dikshit R, Eser S, Mathers C, Rebelo M, Parkin DM, Forman D, Bray F. Cancer incidence and mortality worldwide: sources, methods and major patterns in GLOBOCAN 2012. Int J Cancer. 2015 Mar 1;136(5): E359-86.

3. Irabor DO, Arowolo A, Afolabi AA. Colon and rectal cancer in Ibadan, Nigeria: an update. Colorectal Dis. $2010 \mathrm{Jul}$; 12 (7 Online):e43-9.

4. Alatise OI, Arigbabu AO, Lawal OO, Adetiloye VA, Agbakwuru EA, Ndububa DA. Presentation, distribution pattern, and management of diverticular disease in a Nigerian tertiary hospital. Niger J Clin Pract. 2013 Apr-Jun; 16(2):226-31.

5. Kiguli-Malwadde E, Kasozi H. Diverticular disease of the colon in Kampala, Uganda. Afr Health Sci. 2002 Apr;2(1):29-32.

6. Katsidzira L, Gangaidzo IT, Mapingure MP, Matenga JA. Retrospective study of colorectal cancer in Zimbabwe: colonoscopic and clinical correlates. World J Gastroenterol. 2015 Feb 28; 21(8): 2374-80. 
7. Stollman N, Raskin JB. Diverticular disease of the colon. Lancet. 2004 Feb 21; 363(9409): 631-9.

8. Kang JY, Hoare J, Tinto A, Subramanian S, Ellis C, Majeed A, Melville D, Maxwell JD. Diverticular disease of the colon--on the rise: a study of hospital admissions in England between 1989/1990 and 1999/2000. Aliment Pharmacol Ther. 2003 May 1;17(9):1189-95.

9. Martel J, Raskin JB. History, incidence, and epidemiology of diverticulosis. NDSG. J Clin Gastroenterol. 2008; 42:1125-7.

10. Peery AF, Dellon ES, Lund J, Crockett SD, McGowan CE, Bulsiewicz WJ, Gangarosa LM, Thiny MT, Stizenberg K, Morgan DR, Ringel Y, Kim HP, Dibonaventura MD, Carroll CF, Allen JK, Cook SF, Sandler RS, Kappelman MD, Shaheen NJ. Burden of gastrointestinal disease in the United States: 2012 update. Gastroenterol 2012 Nov;143(5):1179-87.e1-3.

11. Alatise OI, Arigbabu AO, Agbakwuru EA, Lawal OO, Ndububa DA, Ojo OS. Spectrum of colonoscopy findings in Ile-Ife Nigeria. Niger Postgrad Med J. 2012 Dec; 19(4): 219-24.

12. Onyekwere CA, Odiagah JN, Ogunleye OO, Chibututu C, Lesi OA. Colonoscopy practice in Lagos, Nigeria: a report of an audit. Diagn Ther Endosc. 2013; 2013:798651.

13. Ismaila BO, Misauno MA. Gastrointestinal endoscopy in Nigeria--a prospective two-year audit. Pan Afr Med J. 2013; 14:22.

14. Tucker H, George E, Barnett D, Longson C. NICE Technology Appraisal on Stapled Haemorrhoidopexy for the Treatment of Haemorrhoids. Ann R Coll Surg Engl. 2008; 90: 82-84.

15. Kayamba V, Sinkala E, Mwanamakondo S, Soko R, Kawimbe B, Amadi B, Zulu I, Nzaisenga JB, Banda T, Mumbwe C, Phiri E, Munkonge P, Kelly P. Trends in upper gastrointestinal diagnosis over four decades in Lusaka, Zambia: a retrospective analysis of endoscopic findings. BMC Gastroenterol. 2015 Oct 6; 15:127.

16. Ennaifer R, Elleuch N, Sabbagh S, Romdhane H, Hefaiedh R, Ben Nejma H, Belhadj N. Quality indicators for colonoscopy in a Tunisian endoscopy unit. Tunis Med. 2015 Mar;93(3):138-41.

17. Gavin DR, Valori RM, Anderson JT, Donnelly MT, Williams JG, Swarbrick ET. The national colonoscopy audit: a nationwide assessment of the quality and safety of colonoscopy in the UK. Gut. 2013 Feb; 62(2): 242-9.

18. Froehlich F, Wietlisbach V, Gonvers JJ, Burnand B, Vader JP. Impact of colonic cleansing on quality and diagnostic yield of colonoscopy: the European Panel of Appropriateness of Gastrointestinal Endoscopy European multicenter study. Gastrointest Endosc. 2005 Mar; 61(3): 378-84.
19. Graham A, Adeloye D, Grant L, Theodoratou E, Campbell H. Estimating the incidence of colorectal cancer in Sub-Saharan Africa: A systematic analysis. J Glob Health. 2012 Dec; 2(2):020404.

20. Colorectal cancer statistics, http://www.cdc.gov/cancer/colorectal/ statistics/index.htm, accessed on October 31st 2016.

21. Veruttipong D, Soliman AS, Gilbert SF, Blachley TS, Hablas A, Ramadan M, Rozek LS, Seifeldin IA. Age distribution, polyps and rectal cancer in the Egyptian population-based cancer registry. World $\mathrm{J}$ Gastroenterol. 2012 Aug 14;18(30):3997-4003.

22. SEER Stat Fact Sheets: Colon and Rectum Cancer, http://seer. cancer.gov/statfacts/html/colorect.html, accessed on October 31st 2016.

23. Ogutu EO, Okoth FA, Lule GN. Colonoscopic findings in Kenyan African patients. East Afr Med J. 1998 Sep;75(9):540-3.

24. Heitman SJ, Ronksley PE, Hilsden RJ, Manns BJ, Rostom A, Hemmelgarn BR. Prevalence of adenomas and colorectal cancer in average risk individuals: a systematic review and meta-analysis. Clin Gastroenterol Hepatol. 2009 Dec;7(12):1272-8.

25. Segal I, Walker AR. Diverticular disease in urban Africans in South Africa. Digestion. 1982; 24(1): 42-6.

26. Burkitt D. Diverticular disease of the colon epidemiological evidence relating it to fibre-depleted diets. Trans Med SocLond 1973; 89: $81-4$.

27. Segal I, Solomon A, Hunt JA. Emergence of diverticular disease in the urban South African black. Gastroentrol. 1977 Feb; 72(2): 215-9.

28. Strate LL. Diverticulosis and dietary fiber: rethinking the relationship. Gastroentrol. 2012 Feb; 142(2): 205-7.

29. Vajrabukka T, Saksornchai K, Jimakorn P. Diverticular disease of the colon in a far-eastern community. Dis Colon Rectum. 1980 Apr; 23(3): 151-4

30. Riss S, Weiser FA, Riss T, Schwameis K, Mittlböck M, Stift A. Haemorrhoids and quality of life. Colorectal Dis. 2011 Apr; 13(4):e4852 .

31. Lee JH, Kim HE, Kang JH, Shin JY, Song YM. Factors associated with hemorrhoids in korean adults: korean national health and nutrition examination survey. Korean J Fam Med. 2014; 35: 227-236.

32. Riss S, Weiser FA, Schwameis K, Riss T, Mittlböck M, Steiner G, Stift A. The prevalence of hemorrhoids in adults. Int J Colorectal Dis. 2012 Feb; 27(2): 215-20. 